\title{
Using squeeze-film effect to reduce surface friction in electrostatic actuators
}

\author{
Zsurzsan, Tiberiu-Gabriel; Yamamoto, Akio; Zhang, Zhe; Andersen, Nils Axel; Andersen, Michael A. E.
}

Published in:

Proceedings of 6th International Conference on Advanced Mechatronics

Publication date:

2015

Document Version

Peer reviewed version

Link back to DTU Orbit

Citation (APA):

Zsurzsan, T-G., Yamamoto, A., Zhang, Z., Andersen, N. A., \& Andersen, M. A. E. (2015). Using squeeze-film effect to reduce surface friction in electrostatic actuators. In Proceedings of 6th International Conference on Advanced Mechatronics

\section{General rights}

Copyright and moral rights for the publications made accessible in the public portal are retained by the authors and/or other copyright owners and it is a condition of accessing publications that users recognise and abide by the legal requirements associated with these rights.

- Users may download and print one copy of any publication from the public portal for the purpose of private study or research.

- You may not further distribute the material or use it for any profit-making activity or commercial gain

- You may freely distribute the URL identifying the publication in the public portal

If you believe that this document breaches copyright please contact us providing details, and we will remove access to the work immediately and investigate your claim. 


\title{
Using squeeze-film effect to reduce surface friction in electrostatic actuators
}

\author{
Gabriel Zsurzsan*1, Akio Yamamoto*2, Zhe Zhang*1, Nils A. Andersen*1, Michael A.E. Andersen*1 \\ ${ }^{* 1}$ DTU Electrical Engineering, Technical University of Denmark \\ Richard Petersens Plads byg. 325, Kgs. Lyngby, Denmark \\ ${ }^{* 2}$ Department of Precision Engineering, Graduate School of Engineering, The University of Tokyo \\ 7-3-1 Hongo, Bunkyo-ku, Tokyo, 113-8656 Japan
}

This paper presents a method of reducing load friction in two degrees-of-freedom (2-DOF) transparent electrostatic induction actuator by using vibration-induced squeeze film effect. An experimental set-up was built to prove the concept. An overall $70 \%$ reduction in required driving voltage was obtained when the squeeze film is present.

\section{Introduction}

Electrostatic film actuators are thin, lightweight and flexible actuators composed of fully transparent plastic films etched with fine-pitched electrodes. They have very wide areas of application such as particle transportation or flexible muscle actuation, but feature most prominently in haptcis and human-machine interfaces where their transparency allows them to be overlaid onto any traditional display surface or game board. This allows enhancing these interfaces with actuation, motion and feedback capabilities [1-4].

Despite their usefulness, a disadvantage of electrostatic actuators is the fact that they require a layer of very small glass beads between stator and slider films to act as both gap material and friction reducer. This reduces the feasibility of the actuators since the glass beads require periodic reapplication and also create a mess around the area in use.

The necessity for glass beads can be reduced or totally eliminated by inducing a squeeze film between the contact surfaces through controlled piezoelectric vibration. This vibration traps a very thin layer of air (or any other gas) between parallel plate surfaces thereby creating the squeeze film effect [5-12]. This thin air layer can successfully substitute the use of glass beads in electrostatic film actuators.

\section{Study of glass plate vibration}

The transparent electrostatic actuator consists of a layer of film with electrodes printed onto a large glass plate substrate. A large voltage is applied to the electrodes, whereby an electrostatic force is exerted upon a dielectric sheet placed on top. This controllable force enables the dielectric sheet to move across the surface. Small glass beads need to be spread onto the actuator surface in order to both provide an air gap and reduce friction between actuated sheet and actuator surface.

In order to eliminate the need for these beads, squeeze film effect is employed. The squeeze film effect is the effect whereby a very thin layer of gas gets trapped between relatively large, parallel plate surfaces if these are kept in relative motion versus one another. This effect is the result of an overpressure phenomenon present between the surfaces.

The design methodology closely follows the one presented in [13], with a significant difference in the size scope of the

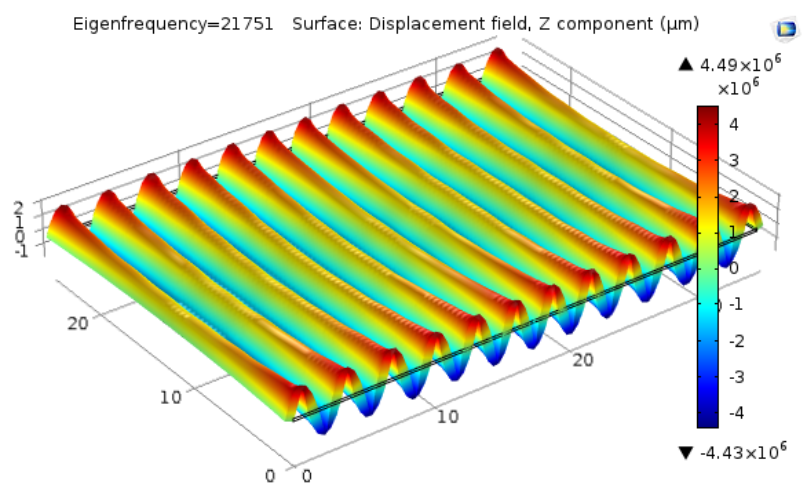

Fig. 1 Snapshot of time-domain vibration propagation analysis in the glass plate subjected to sinusoidal excitation at $21.7 \mathrm{kHz}$.

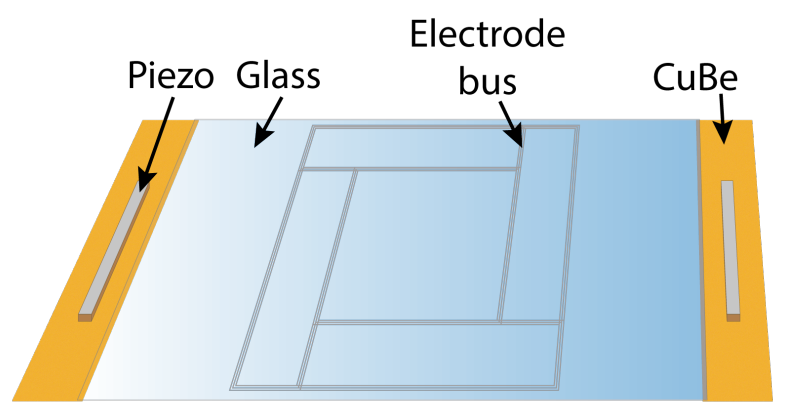

Fig. 2 Resonating glass-base electrostatic actuator system sketch.

application. While Giraud et al. employ the effect for tactile friction modulation on a relatively small 4.3 inch LCD, the plate used as base for the electrostatic actuator measures $345 \mathrm{~mm}$ in length, its width is $250 \mathrm{~mm}$ with a thickness of $1.8 \mathrm{~mm}$. A full modal, frequency and time analysis of the vibration of such a size plate is performed in order to size the required actuators to excite the correct mode of vibration, beyond human hearing range. One such mode obtained is at $21.7 \mathrm{kHz}$. The resulting vibration half-wavelength is $15 \mathrm{~mm}$. This is shown in Fig. 1.

\section{System design}

In order to excite the glass plate to vibrate at the obtained resonant frequency, two copper-berylium resonators with attached piezoelectric actuators were sized and glued to the glass plate through epoxy resin. The resonators measure $250 \mathrm{~mm} \times 50 \mathrm{~mm} \times 2 \mathrm{~mm}$, where the long edge has to fit the glass plate while the width is determined by the desired resonance frequency. The initial design used six $11 \mathrm{~mm}$ x $50 \mathrm{~mm}$ $\mathrm{x} 1 \mathrm{~mm}$ piezos on each resonator, designed to operate in $\mathrm{d} 31$ 


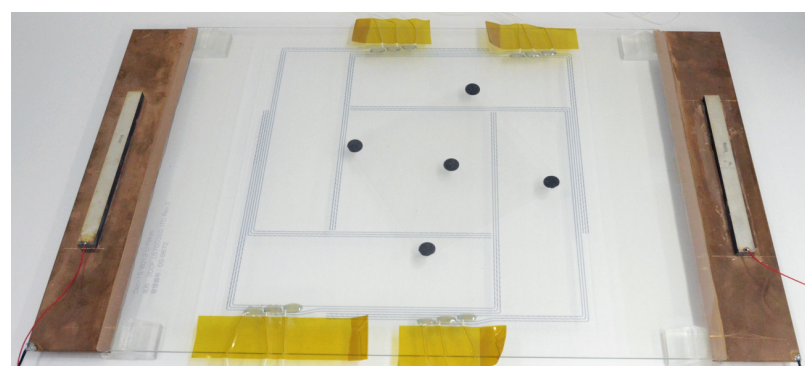

Fig. 3 Photo of the final system, with plastic actuated sheet shown on top of the actuator surface.

mode. Due to long delivery time of the desired piezos, these were substituted with two $120 \mathrm{~mm}$ x $10 \mathrm{~mm}$ x $5 \mathrm{~mm}$ actuators which were readily available. The difference in size with respect to the original design resulted in a resonance frequency shift of the entire system into the audible range. The sketch of the designed system is shown in Fig. 2, while the actual final system is presented in Fig. 3 .

\section{Results and conclusion}

In order to generate a sizable electrostatic force that can overcome stick-slip of the chosen dielectric sheet (visible on top of the actuator surface in Fig. 3) without using any glass beads or squeeze film, a voltage of $500 \mathrm{~V}$ needs to be applied to the electrodes. With the vibration system turned on, this minimum voltage is reduced to only $150 \mathrm{~V}$. That equates to a $70 \%$ reduction in electrostatic voltage requirements to overcome stick-slip, which can be attributed a corresponding reduction in friction between the actuated sheet and actuator surface. Moreover, using the originally-designed piezoelectric actuators would push the system resonance frequency to above hearing range, making it more suitable for human interaction.

All in all, squeeze film effect is successfully employed in order to eliminate the need for glass beads in transparent rigid-plate surface electrostatic actuators, but the actual operation of the actuator seems to depend on other influencing factors, such as humidity. Therefore, the overall system will be the subject of further analysis and improvement.

\section{Acknowledgement}

This work was partly supported by Grant-in-Aid for Scientific Research KAKENHI (B) (No. 26280069) from JSPS, Japan, and partly supported by the Danish High Technology Foundation grant number 054-2011-1.

\section{References}

[1] K. Amano and A. Yamamoto, "Tangible interactions on a flat panel display using actuated paper sheets," ITS 2012 - Proceedings of the ACM Conference on Interactive Tabletops and Surfaces, pp. 351-354, 2012.

[2] T. Hosobata, A. Yamamoto, and T. Higuchi, "2-dof synchronous electrostatic actuator with transparent electrodes arranged in checkerboard patterns," IEEE International Conference on Intelligent Robots and Systems, pp. 6697 066, 4919 4924, 2013.
[3] R. Iguchi, T. Hosobata, and A. Yamamoto, "Transparent electrostatic actuator with mesh-structured electrodes for driving tangible icon in tabletop interface," in Proceedings of the 2014 ACHI International Conference on Advances in ComputerHuman Interactions. IARIA, 2014, pp. 288-293.

[4] N. Yamashita, K. Amano, and A. Yamamoto, "Interaction with real objects and visual images on a flat panel display using three-dof transparent electrostatic induction actuators," in Proceedings of the 2014 ACHI International Conference on Advances in Computer-Human Interactions. IARIA, 2014, pp. 294-299.

[5] R. Pratap, S. Mohite, and A. K. Pandey, "Squeeze film effects in mems devices," Journal of the Indian Institute of Science, vol. 87, no. 1, pp. 75-94, 2007.

[6] S. Bharadwaj and M. J. Dapino, "Effect of load on active friction control using ultrasonic vibrations," Proceedings of SPIE - the International Society for Optical Engineering, Industrial and Commercial Applications of Smart Structures Technologies 2009, vol. 7290, no. 1, p. 72900G, 2009.

[7] M. Biet, F. Giraud, and B. Lemaire-Semail, "Squeeze film effect for the design of an ultrasonic tactile plate," IEEE-ACM Transactions on Networking, vol. 15, no. 6, pp. 2678-2688, 2007.

[8] R. Capozza, A. Vanossi, A. Vezzani, and S. Zapperi, "Suppression of friction by mechanical vibrations," Physical Review Letters, vol. 103, no. 8, p. 085502, 2009.

[9] C. Hudin, J. Lozada, and V. Hayward, "Localized tactile stimulation by time-reversal of flexural waves: case study with a thin sheet of glass," 2013 World Haptics Conference, pp. 6772, 2013.

[10] V. Levesque, L. Oram, K. MacLean, A. Cockburn, N. D. Marchuk, D. Johnson, J. E. Colgate, and M. A. Peshkin, "Enhancing physicality in touch interaction with programmable friction," Conference on Human Factors in Computing Systems - Proceedings, pp. 2481-2490, 2011.

[11] L. Winfield, J. Glassmire, J. E. Colgate, and M. Peshkin, "T-pad: Tactile pattern display through variable friction reduction," Proceedings - Second Joint Eurohaptics Conference and Symposium on Haptic Interfaces for Virtual Environment and Teleoperator Systems, World Haptics 2007, pp. 4145 211, 421-426, 2007.

[12] W. Littmann, H. Storck, and J. Wallaschek, "Reduction of friction using piezoelectrically excited ultrasonic vibrations," Proceedings of SPIE - the International Society for Optical Engineering, Smart Structures and Materials 2001: Damping and Isolation, vol. 4331, pp. 302-311, 2001.

[13] F. Giraud, M. Amberg, B. Lemaire-Semail, and G. Casiez, "Design of a transparent tactile stimulator," Haptics Symposium 2012 - Proceedings, pp. 6183 835, 485-489, 2012. 